\title{
Determination of the Anxiety and Behavior of Children Undergoing Endodontic Treatment Using Manual and Rotary File Systems: A Comparative Clinical Study
}

\author{
Girish Babu KL ${ }^{1}$, Kavyashree Gururaj Hebbar ${ }^{2}$
}

\begin{abstract}
Introduction: Many dentists perform extraction of deciduous teeth that could be preserved by pulpectomy, claiming that the tedious and longer duration of endodontic treatment leads to development of anxiety and negative behavior in children.

Aim: To determine and compare the anxiety experienced and behavior exhibited by children undergoing endodontic treatment using manual and rotary file systems.

Methods: This clinical study comprised 150 children. The pulpectomy procedure was carried out in the two visits. The first visit consisted of administration of local anesthesia, isolation, access cavity preparation, and pulp extirpation. In the second visit, the children were grouped into 3 groups (Group 1, Group 2, and Group 3) consisting of 50 children each. In groups 1, 2, and 3, root canals were instrumented using the Kedo-S pediatric rotary file system, HERO shaper rotary file systems, and manual Ni-Ti K files, respectively. Root canal instrumentation time was calculated. Anxiety and behavior of children during root canal instrumentation were assessed.

Results: The mean instrumentation time for groups 1, 2, and 3 were $14.56 \pm 2.89$ minutes, $17.93 \pm 3.51$ minutes, and $29.00 \pm 2.08$ minutes, respectively. The children in groups 1 and 2 experienced significantly less anxiety and exhibited positive behavior than children in group 3 .

Conclusion: The children treated with rotary file systems experienced less anxiety and exhibited positive behavior compared to children treated with the manual file systems.
\end{abstract}

Keywords: Anxiety, Behavior, Manual files, Root canal instrumentation time, Rotary files.

Journal of South Asian Association of Pediatric Dentistry (2021): 10.5005/jp-journals-10077-3101

\section{INTRODUCTION}

Dental anxiety is a common problem that affects all ages but is more commonly seen in childhood and adolescence. ${ }^{1}$ The prevalence of dentalanxiety in children ranges from $14.6-39 \% .^{2,3}$ and the prevalence of uncooperative behavior ranges from $8.9-25.2 \%{ }^{4-6}$ Previous studies have reported a relationship between the level of dental anxiety and the behavior of the child in a dental operatory., ${ }^{7,8}$ Both, levels of anxiety and behavior depend on the type and duration of the dental procedures as well as the rapport between the patient and pediatric dentist. ${ }^{9,10}$ Interestingly, it has been noted that the treatment duration of patients with anxiety or behavior management problem is on average $40 \%$ more than that of normal patients going through the same procedure. ${ }^{11}$ Previous studies have evaluated the anxiety level and behavior during non-invasive (oral prophylaxis, fluoride application, and restoration) and invasive (endodontic treatment and extractions) dental procedures and concluded that the invasive treatment procedures increase anxiety and create negative behavior in children. ${ }^{2-6,12}$ However, the importance of treatment duration as an extrinsic determinant factor of child anxiety and behavior has simply been overlooked. ${ }^{13}$

Many dentists perform extraction of deciduous teeth that could be preserved by pulpectomy, claiming that the tedious and longer duration of endodontic treatment leads to the development of negative behavior in child. ${ }^{11,12}$ This may be because root canal preparation in primary teeth is routinely carried out using manual instruments which are time-consuming. The introduction of rotary

\begin{abstract}
1-2Department of Dentistry, Hassan Institute of Medical Sciences, Hassan, Karnataka, India

Corresponding Author: Girish Babu KL, Department of Dentistry, Hassan Institute of Medical Sciences, Hassan, Karnataka, India, Phone: +919845340753, e-mail: docgirish77@gmail.com

How to cite this article: Babu KLG, Hebbar KG. Determination of the Anxiety and Behavior of Children Undergoing Endodontic Treatment Using Manual and Rotary File Systems: A Comparative Clinical Study. J South Asian Assoc Pediatr Dent 2021;4(3):175-184.
\end{abstract}

Source of support: Nil

Conflict of interest: None

endodontics in pediatric dentistry has led to a reduction in root canal instrumentation time with superior and uniform obturation in primary teeth..$^{14,15}$ They also eliminate the problems during the preparation of curved root canals and result in better conservation of the tooth structure. ${ }^{16-18}$ With these options, dentists can perform the pulpectomy with less psychological trauma to the child thus decreasing the anxiety and instilling positive behavior. The acceptance rate of the proposed method of treatment by the child may also increase. Furthermore, the use of a rotary file system may maintain a balance between the treatment duration and efficient behavior management in children.

The review of the literature demonstrated only four studies over the past 50 years that investigated the effect of duration of treatment on children's anxiety and behavior. ${ }^{19-22}$ However, these

(c) The Author(s). 2021 Open Access This article is distributed under the terms of the Creative Commons Attribution 4.0 International License (https://creativecommons. org/licenses/by-nc/4.0/), which permits unrestricted use, distribution, and non-commercial reproduction in any medium, provided you give appropriate credit to the original author(s) and the source, provide a link to the Creative Commons license, and indicate if changes were made. The Creative Commons Public Domain Dedication waiver (http://creativecommons.org/publicdomain/zero/1.0/) applies to the data made available in this article, unless otherwise stated. 
studies have given an inconclusive reports. Therefore, there is a serious need to further investigate the effect of the duration of treatment on children's anxiety and behavior. To the best of our knowledge, no study has assessed the changes in anxiety and behavior in children treated for endodontic treatment using different file systems. Hence, the purpose of this study was to determine and compare the anxiety experienced and behavior exhibited by children undergoing endodontic treatment using rotary and manual file systems.

\section{Methods}

Before commencing this study, ethical clearance was obtained from the institutional review board. The study protocol followed the guidelines provided by the World Medical Association's Declaration of Helsinki on ethical principles for medical research. The CONSORT guidelines for planning and reporting clinical trials in pediatric endodontics were followed throughout the different stages of the study (Fig. 1).

\section{Sample Size Calculation}

The sample size was calculated based on the previous studies ${ }^{17,18}$ with $95 \%$ power. The estimated sample size was 45 which was rounded off to 50 .
The study sample included cooperative children without any confounding physical, mental and medical history, aged 4-7 years visiting our department for pulpectomy of their primary molars. The nature and objectives of the study were explained to the parents of the participating children and their informed written consent was obtained. The participants' confidentiality was ensured with the use of identification numbers, and their records were maintained by the principal investigator alone. Following recording the patient's histories, the intraoral examination was carried out and a standardized intraoral periapical radiograph was taken for the teeth with a possible indication for pulpectomy. The children and their caregivers were then invited to participate in the study.

\section{Inclusion Criteria ${ }^{13,19,23}$}

- Children with no history of dental treatment.

- Children with no history of post-traumatic stress disorders or specific phobia-related dental settings.

- Children with no history of unpleasant experiences in medical settings.

- Children with no previous experience of intraoral injections.

- Children with non-use of medications that affect the central nervous system.

- Children with no history of pain syndromes such as hyperalgesia or allodynia.

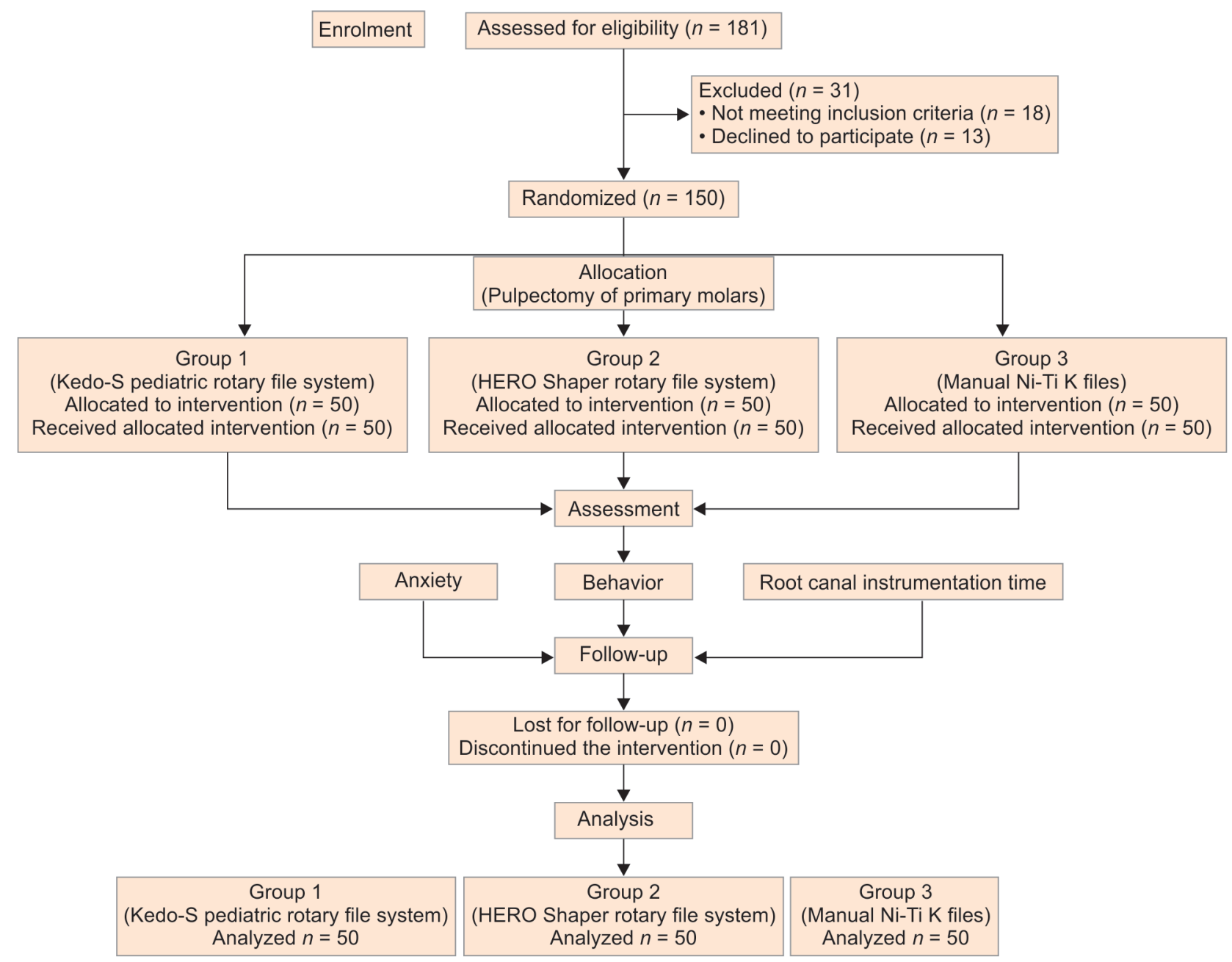

Fig. 1: Flowchart followed during the clinical study 


\section{Exclusion Criteria ${ }^{14,15,24,25}$}

- Children with special healthcare needs.

- Children with rampant caries or developmental anomalies.

- Children with a history of neuropsychiatric disabilities that influence the behavior.

- Children with limited or lacking cooperative abilities.

- Children requiring sedation/general anesthesia for behavior management.

- Children with treatment that could not be completed by principal investigators due to technical problems.

The study comprised 150 children and teeth requiring pulpectomy were selected from them. Periapical status was examined via periapical radiographs. The primary molars with a diagnosis of irreversible pulpitis and radiographic evidence of the presence of more than two-thirds of the root length, absence of a periapical lesion, and inter radicular radiolucency were selected for the study. ${ }^{24,25}$ The pulpal status was confirmed on access opening with presence (vital) or absence (non-vital) of hemorrhage. Only primary molar requiring vital pulpectomy treatments were included. The primary molars with necrotic pulp or abscess or sinus tract and radiographic evidence of pulpal floor perforation and excessive pathological loss of bone support were excluded. ${ }^{24,25}$

\section{Clinical Procedure}

In the initial visit, the children were given a brief tour of the dental operatory. They were guided about the procedure protocol using communication and the Tell-show-do technique. All instruments and tasks were described to them. In the second and third visits, the operator rendered identical treatments to all children that included oral prophylaxis and fluoride application at the beginning followed by glass ionomer cement restoration. The total treatment duration was not more than 30 minutes in each visit. Following these visits, the pulpectomy procedure was carried out under stringent aseptic conditions by a single pediatric dentist with experience using both rotary and manual instrumentation techniques. The pulpectomy procedure was carried out in the two visits. The first visit consisted of administration of local anesthesia, isolation, access cavity preparation, and pulp extirpation. The routine procedure protocol for pulpectomy was followed that remained the same to all children to control the possible bias. ${ }^{17,18}$ The second visit was scheduled after 7 days (i.e., $8^{\text {th }}$ day). In this visit, computer-generated randomization was used to sort the selected children into three groups (group 1, group 2, and group 3), each consisting of 50 children. In group 1, root canals were instrumented using the Kedo-S pediatric rotary file system (Reeganz Dental Care Pvt. Ltd, India) following the manufacturer's instructions. ${ }^{18}$ In group 2 , the root canals were instrumented with the HERO shaper rotary file system (Micromega, Geneva, Switzerland) together with a coronal enlarging file (Endoflare- Micromega, Geneva, Switzerland) provided with the file system. The enlargement of the root canals up to the working length was done according to the sequence recommended by the manufacturer. ${ }^{17}$ The rotary file systems of groups 1 and 2 were used with an endodontic motor (X-Smart, Dentsply Maillefer, OK, USA) at $300 \mathrm{rpm}$ and $2.2 \mathrm{Ncm}$ torque. ${ }^{18}$ In group 3 , root canals were instrumented with manual Ni-Ti K files (Dentsply, Switzerland). A minimum-size file provided resistance for intracanal placement until the working length was determined as an initial file. The root canals were enlarged up to three times the size of the initial file. Then, the root canals were cleaned and shaped using a pullback motion. ${ }^{18}$ In all the groups, each file was used for up to five teeth to maintain uniformity during root canal preparation. ${ }^{18}$ In all children, root canals were prepared with intermittent irrigation using a standard volume of $5 \mathrm{~mL}$ of normal saline. As a lubricating paste, during root canal preparation, 17\% EDTA gel (RC Help, Prime Dental Products, Pvt. Ltd.) was used. Following complete root canal preparation, final irrigation with saline was carried out and the root canals were dried using absorbent paper points. The root canals of the primary molars of all groups were obturated with zinc oxide eugenol cement (Zinc Oxide BP, Eugenol BP, Associated Dental Products Ltd) using a Lentulo-spiral mounted on a slow-speed handpiece. A post-obturation radiograph was taken to assess the quality of obturation. The pulp chamber was cleaned with a moist cotton pellet followed by restoration with type II glass ionomer cement (GC, India). The final restoration with stainless steel crowns (3M ESPE, Sr Paul, MN, USA) was given in the next appointment within one week following obturation. All the participants were instructed to report in case of any symptoms such as pain or swelling. The parent/caregiver was present during all visits of treatment. The total treatment duration was not more than 30 minutes in each visit. To keep the uniformity in the timing of treatment, all children were treated in the morning session between $10 \mathrm{am}$ to $12 \mathrm{pm}$.

During the first and second visits of pulpectomy, the anxiety and behavior of the child were assessed using the clinical anxiety scale and Frankl-behavior scale, respectively. ${ }^{26,27}$ Anxiety and behavior were assessed at the first visit of pulpectomy that was divided into the following five phases: (1) Phase 1: 5 minutes before the start of the treatment. (2) Phase 2: During the administration of local anesthesia. (3) Phase 3: During access cavity preparation. (4) Phase 4: During pulp extirpation. (5) Phase 5: 5 minutes after the completion of treatment. To assess the anxiety and behavior, the second visit (root canal instrumentation procedure) was divided into four phases: (1) Phase 1:5 minutes before the start of the instrumentation of the root canal. (2) Phase 2: During instrumentation of root canal. (3) Phase 3: Immediately after instrumentation of root canal. (4) Phase 4: 5 minutes after the completion of the instrumentation of the root canal. Root canal instrumentation time was calculated by a trained dental assistant using a stopwatch. Instrumentation time was the time required to negotiate and shape the root canals to the desired size after root canal access opening and working length determination. ${ }^{18,25}$

Participants, outcome assessors, and data analysts were blinded about the type of instrumentation used; however, the operator could not be blinded because of the recognizable characteristics of the rotary or manual files. The anxiety, behavior, and instrumentation time were assessed and recorded by the second investigator who was blinded for the type of instrumentation used. The investigator was calibrated and trained to become familiar with the rating scales used. The Kappa value for intra-examiner agreement of data was 0.88 (excellent). For the inter-examiner agreement of data, on a random basis, another examiner determined the anxiety and behavior along with the second investigator.

\section{Statistical Analysis}

The data obtained were entered into a Microsoft excel sheet and statistically analyzed using SPSS 22.0 statistical software and R environment ver. 3.2.2 19.0 (IBM Corp. Released 2010. IBM SPSS Statistics for Windows, Version 19.0. Armonk, NY: IBM Corp.) The data obtained for the first visit of pulpectomy were expressed as a percentage. Descriptive and inferential statistical analysis was carried out. Results on continuous measurements are presented 
on Mean $\pm S D$ (min-max) and results on categorical measurements are presented in number (\%). Significance was assessed at a 5 $\%$ level of significance. Kruskal Wallie's test for non-parametric cases in the condition of three or more groups was employed. Mann Whitney U test (two-tailed, independent) was used to find the significance of study parameters on the continuous scale but non-parametric between two groups (Intergroup analysis) on metric parameters. Chi-square/Fisher exact test was used to find the significance of study parameters on a categorical scale between two or more groups, a non-parametric setting for qualitative data analysis. Fisher exact test was used when cell samples are very small.

\section{Results}

A total of 150 children with a mean age of $5.67 \pm 0.17$ years participated in the study. Among the children, 68 were females and 82 were males. There was no statistical significance in the distribution of primary molars among all three groups. The mean instrumentation times for groups 1, 2, and 3 were $14.56 \pm 2.89$ minutes, $17.93 \pm$ 3.51 minutes, and $29.00 \pm 2.08$ minutes, respectively. The mean difference of instrumentation time between groups 1 and 3 and between groups 2 and 3 were statistically significant (Tables 1). In the first visit of pulpectomy, $13 \%, 37 \%$, and $36 \%$ of children scored 4, 3, and 2, respectively, for anxiety during phase 2 (during the administration of local anesthesia) (Table 2). Eighty percent of children exhibited negative behavior during this phase. Most of the children experienced less anxiety and exhibited positive behavior in the following phases. In the second visit, almost $47 \%$ of children scored 0 and $30 \%$ of them scored 1 of dental anxiety during phase 2 (during root canal instrumentation). In phases 2 and 3, the children experienced less anxiety in groups 1 and 2 compared to group 3, which was statistically significant (Table 3). On the assessment of behavior, $82 \%$ of children exhibited Rating 3 followed by Rating 4 (17\%). A higher number of children in groups 1and 2 exhibited positive behavior compared to group 3 . This difference was significant in all the phases (Table 4). The anxiety experienced and behavior exhibited were statistically significant during the instrumentation phase. The overall comparison showed that the children in groups 1 and 2 experienced less anxiety and exhibited positive behavior than children in group 3. The anxiety of children decreased further and they exhibited positive behavior in the following phases.

In comparison between genders, there was no significant difference in anxiety experienced or behavior (Tables 5 and 6). A significant variation in anxiety was observed in the comparison between age-groups, but not with behavior (Table 5). On the correlation between mean instrumentation time and anxiety and behavior, there was a negative correlation in groups 1 and 2 but not with group 3 (Table 7).

\section{Discussion}

Endodontic treatment in primary teeth is a long-winded procedure that becomes challenging when it is coupled with poor behavior and anxiety. Root canal preparation is routinely carried out with the time-consuming manual file system and has a risk of accidental slippage into the respiratory tract. Rotary endodontics has significantly reduced the root canal instrumentation time and it is safer to use in children as these files are attached to the handpiece of the endomotor. Thus, the pulpectomy can be carried out with less anxiety and positive behavior with increased acceptance by children.

An accurate understanding of children's anxiety and behavior using a proper screening tool is the primary setup for effective management of anxious children. One of the most widely used scales is the clinical anxiety rating scale. ${ }^{26}$ Frankl's behavioral rating scale is often considered as the "gold standard" of classifying the behavior of the child in the dental operatory and it is widely used and well accepted by the pediatric dentist. ${ }^{27}$ The time point at which dental anxiety and fear are measured can also affect the outcomes. In addition, it is important to consider the time frame of the assessment to evaluate the dynamic process of change. ${ }^{28}$ Anxiety assessment postoperatively is questionable as children who recovered may rate the treatment procedure more positively than they actually felt. ${ }^{29}$ Hence, the anxiety and behavior were measured in the fixed time frame (fore-noon) at the four-time point during root canal instrumentation.

Many factors could trigger dental anxiety and uncooperative behavior. The main factors are child-dentist relationships, maternal characteristics, personality traits, and general fears. ${ }^{30-33}$ The strength and nature of previous dental and medical experience, the number, and the combination of the experiences seem to have stronger associations with dental anxiety and fear. ${ }^{29}$ Some of the anxiety-causing equipment and materials used in dental operatory are the use of local anesthesia, unpleasant and unfamiliar tastes, and fear of blood. ${ }^{34,35}$ Thus, we selected children with no previous dental experience and they were introduced to child-friendly dental operatory and also explained about dental materials and equipment in the initial visits before starting the endodontic treatment.

Age is a well-established factor that determines children's anxiety and behavior in the dental office. Children develop emotionally, socially, and cognitively throughout the developing years. Mental development affects whether children can learn to accept dental treatment or not. ${ }^{36}$ Children's attitudes toward dentistry are largely shaped by emotional meaning and it changes with emotional development. ${ }^{37}$ An older child is expected to cope better with dental treatment better than a younger one and will be able to understand and comprehend the instructions given by the dentist better, and also express their feeling and perceptions more clearly. ${ }^{38}$ In addition, they better understand that there is no

Table 1: Comparison of mean instrumentation time (in minutes) between three groups

\begin{tabular}{lccc}
\hline Groups & $n$ & Mean $\pm S D$ & $p$-value \\
\hline Group 1 & 50 & $14.56 \pm 2.89$ & $<0.001^{*}$ \\
Group 2 & 50 & $17.93 \pm 3.51$ & \\
Group 3 & 50 & $29.00 \pm 2.08$ & \\
\hline
\end{tabular}

Kruskal Wallis Test ${ }^{*}$ statistically significant [+ Suggestive significance- $p$ value: $0.05<p<0.10,{ }^{*}$ Moderately significant- $p$ value: $0.01<p \leq 0.05$ ] 
Root Canal Instrumentation Time and Anxiety and Behavior

Table 2: Dental anxiety and behavior of children during the first visit of pulpectomy

\begin{tabular}{|c|c|c|c|}
\hline \multicolumn{2}{|c|}{ Anxiety experienced } & \multicolumn{2}{|l|}{ Behavior exhibited } \\
\hline Score & $\begin{array}{l}\text { Total } \\
n(\%)\end{array}$ & Score & $\begin{array}{l}\text { Total } \\
n(\%)\end{array}$ \\
\hline \multicolumn{4}{|c|}{ Phase 1: 5 minutes before the start of the treatment } \\
\hline Score 0 & $116(77.33)$ & Rating 1 (Definitively positive) & $15(10)$ \\
\hline Score 1 & $34(22.66)$ & Rating 2 (Positive) & $123(82)$ \\
\hline Score 2 & 0 & & \\
\hline Score 3 & 0 & Rating 3 (Negative) & $12(8)$ \\
\hline Score 4 & 0 & Rating 4 (Definitively negative) & 0 \\
\hline Score 5 & 0 & & \\
\hline \multicolumn{4}{|c|}{ Phase 2: During the administration of local anesthesia } \\
\hline Score 0 & $3(2)$ & Rating 1 (Definitively positive) & 0 \\
\hline Score 1 & $13(8.6)$ & Rating 2 (Positive) & $34(22.6)$ \\
\hline Score 2 & $54(36)$ & & \\
\hline Score 3 & $55(37)$ & Rating 3 (Negative) & $120(80)$ \\
\hline Score 4 & $20(13.33)$ & Rating 4 (Definitively negative) & $06(4)$ \\
\hline Score 5 & 0 & & \\
\hline \multicolumn{4}{|c|}{ Phase 3: During access cavity preparation } \\
\hline Score 0 & $35(23)$ & Rating 1 (Definitively positive) & $5(3.33)$ \\
\hline Score 1 & $70(46)$ & Rating 2 (Positive) & $89(59.33)$ \\
\hline Score 2 & $25(16)$ & & \\
\hline Score 3 & $20(13)$ & Rating 3 (Negative) & $53(35.3)$ \\
\hline Score 4 & 0 & Rating 4 (Definitively negative) & $3(2)$ \\
\hline Score 5 & 0 & & \\
\hline \multicolumn{4}{|c|}{ Phase 4: During pulp extirpation } \\
\hline Score 0 & $90(60)$ & Rating 1 (Definitively positive) & $13(8.6)$ \\
\hline Score 1 & $45(30)$ & Rating 2 (Positive) & $125(83.33)$ \\
\hline Score 2 & $15(10)$ & & \\
\hline Score 3 & 0 & Rating 3 (Negative) & $12(8)$ \\
\hline Score 4 & 0 & Rating 4 (Definitively negative) & 0 \\
\hline Score 5 & 0 & & \\
\hline \multicolumn{4}{|c|}{ Phase 5: 5 minutes after the completion of treatment } \\
\hline Score 0 & $146(98)$ & Rating 1 (Definitively positive) & $13(8.6)$ \\
\hline Score 1 & $5(2)$ & Rating 2 (Positive) & $137(91.3)$ \\
\hline Score 2 & 0 & & \\
\hline Score 3 & 0 & Rating 3 (Negative) & 0 \\
\hline Score 4 & 0 & Rating 4 (Definitively negative) & 0 \\
\hline Score 5 & 0 & & \\
\hline
\end{tabular}

reason to misbehave when treatment is over and in absence of pain. However, young children may feel that, as long as they are still in the dental operatory, the treatment is not ended. ${ }^{19,22}$ Davidovich et al. ${ }^{22}$ and Aminabadi et al..$^{19}$ reported a significant deterioration of behavior in younger children as treatment time increased. They stated that the emergence of misbehavior is age-dependent and it is more gradual and linear. Further, they stated that older children can be easily controll in clinical settings through the application of proper behavior guidance strategies and treatment duration may be extended from 40 to 60 minutes. Our findings are consistent with these studies. ${ }^{19,22}$ Thus, there is necessary to effectively establish a trusting relationship, good communication skills, empathy, caring and step-wise treatment, shorter treatment duration, and use of some basic non-pharmacological approaches during the management of children. Our study did not show any statistically significant relationship between gender and children's anxiety and behavior. In accordance with our results, Suprabha et al. reported that the gender of the child was unrelated to the behavior. ${ }^{39}$ Additionally, Kyritsi et al. while studying the Greek population also found that the dental behavior was unrelated to gender but was related to the age of the child. ${ }^{40}$

Treatment duration may affect the anxiety and behavior of pediatric patients in combination with chronological age. ${ }^{19}$ There is a lack of general agreement on the optimal duration of treatment in child dental patients. There is no study explicitly investigating the most appropriate length of dental treatment for children. ${ }^{41}$ The sustained attention span of children is the major determinant of their reaction to the duration of treatment. ${ }^{19}$ Researchers suggest treatment should be limited to 15 minutes for children up to five years of age..$^{21,42}$ The shorter appointments have been suggested 
Root Canal Instrumentation Time and Anxiety and Behavior

Table 3: Dental anxiety experienced by children during the second visit of pulpectomy

\begin{tabular}{|c|c|c|c|c|c|}
\hline Anxiety experienced & $\begin{array}{l}\text { Group } 1 \\
(n=50)\end{array}$ & $\begin{array}{l}\text { Group } 2 \\
(n=50)\end{array}$ & $\begin{array}{l}\text { Group } 3 \\
(n=50)\end{array}$ & $\begin{array}{l}\text { Total } \\
(n=150)\end{array}$ & $p$-value \\
\hline \multicolumn{5}{|c|}{ Phase 1: 5 min before the start of the instrumentation of root canal } & 0.369 \\
\hline Score 0 & $33(66 \%)$ & $34(68 \%)$ & $39(78 \%)$ & 106 (70.7\%) & \\
\hline Score 1 & $17(34 \%)$ & $16(32 \%)$ & $11(22 \%)$ & $44(29.3 \%)$ & \\
\hline Score 2 & $0(0 \%)$ & $0(0 \%)$ & $0(0 \%)$ & $0(0 \%)$ & \\
\hline Score 3 & $0(0 \%)$ & $0(0 \%)$ & $0(0 \%)$ & $0(0 \%)$ & \\
\hline \multicolumn{5}{|c|}{ Phase 2: During instrumentation of root canal } & $<0.001^{* * *}$ \\
\hline Score 0 & $33(66 \%)$ & $27(54 \%)$ & $10(20 \%)$ & $70(46.7 \%)$ & \\
\hline Score 1 & $13(26 \%)$ & $21(42 \%)$ & $11(22 \%)$ & $45(30 \%)$ & \\
\hline Score 2 & $4(8 \%)$ & $2(4 \%)$ & $24(48 \%)$ & $30(20 \%)$ & \\
\hline Score 3 & $0(0 \%)$ & $0(0 \%)$ & $5(10 \%)$ & $5(3.3 \%)$ & \\
\hline \multicolumn{5}{|c|}{ Phase 3: Immediately after instrumentation of root canal } & $0.043^{*}$ \\
\hline Score 0 & $33(66 \%)$ & $30(60 \%)$ & $21(42 \%)$ & $84(56 \%)$ & \\
\hline Score 1 & $13(26 \%)$ & $15(30 \%)$ & $14(28 \%)$ & $42(28 \%)$ & \\
\hline Score 2 & $4(8 \%)$ & $5(10 \%)$ & $13(26 \%)$ & $22(14.7 \%)$ & \\
\hline Score 3 & $0(0 \%)$ & $0(0 \%)$ & $2(4 \%)$ & $2(1.3 \%)$ & \\
\hline \multicolumn{5}{|c|}{ Phase 4: 5 min after the completion of the instrumentation of root canal } & 0.107 \\
\hline Score 0 & $50(100 \%)$ & $50(100 \%)$ & $47(94 \%)$ & $147(98 \%)$ & \\
\hline Score 1 & $0(0 \%)$ & $0(0 \%)$ & $3(6 \%)$ & $3(2 \%)$ & \\
\hline Score 2 & $0(0 \%)$ & $0(0 \%)$ & $0(0 \%)$ & $0(0 \%)$ & \\
\hline Score 3 & $0(0 \%)$ & $0(0 \%)$ & $0(0 \%)$ & $0(0 \%)$ & \\
\hline
\end{tabular}

Chi-square test [+ Suggestive significance- $p$ value: $0.05<p<0.10,{ }^{*}$ Moderately significant- $p$ value: $0.01<p \leq 0.05,{ }^{* *}$ Strongly significant- $p$ value: $\leq 0.01$ ]

Table 4: Behavior exhibited by children during second visit of pulpectomy

\begin{tabular}{|c|c|c|c|c|c|}
\hline Behavior exhibited & $\begin{array}{l}\text { Group } 1 \\
(n=50)\end{array}$ & $\begin{array}{l}\text { Group } 2 \\
(n=50)\end{array}$ & $\begin{array}{l}\text { Group } 3 \\
(n=50)\end{array}$ & $\begin{array}{l}\text { Total } \\
(n=150)\end{array}$ & P-Value \\
\hline \multicolumn{5}{|c|}{ Phase 1:5 min before the start of the instrumentation of root canal } & $<0.001^{* *}$ \\
\hline Rating 1 & $0(0 \%)$ & $0(0 \%)$ & $0(0 \%)$ & $0(0 \%)$ & \\
\hline Rating 2 & $2(4 \%)$ & $2(4 \%)$ & $0(0 \%)$ & $4(2.7 \%)$ & \\
\hline Rating 3 & $48(96 \%)$ & $48(96 \%)$ & $43(86 \%)$ & $139(92.7 \%)$ & \\
\hline Rating 4 & $0(0 \%)$ & $0(0 \%)$ & $7(14 \%)$ & $7(4.7 \%)$ & \\
\hline \multicolumn{5}{|c|}{ Phase 2: During instrumentation of root canal } & $<0.001^{* *}$ \\
\hline Rating 1 & $0(0 \%)$ & $0(0 \%)$ & $0(0 \%)$ & $0(0 \%)$ & \\
\hline Rating 2 & $1(2 \%)$ & $0(0 \%)$ & $0(0 \%)$ & $1(0.7 \%)$ & \\
\hline Rating 3 & 47 (94\%) & 44 (88\%) & 32 (64\%) & $123(82 \%)$ & \\
\hline Rating 4 & $2(4 \%)$ & $6(12 \%)$ & $18(36 \%)$ & $26(17.3 \%)$ & \\
\hline \multicolumn{5}{|c|}{ Phase 3: Immediately after instrumentation of root canal } & $<0.001^{* *}$ \\
\hline Rating 1 & $0(0 \%)$ & $0(0 \%)$ & $0(0 \%)$ & $0(0 \%)$ & \\
\hline Rating 2 & $2(4 \%)$ & $1(2 \%)$ & $0(0 \%)$ & $3(2 \%)$ & \\
\hline Rating 3 & 48 (96\%) & 46 (92\%) & 35 (70\%) & $129(86 \%)$ & \\
\hline Rating 4 & $0(0 \%)$ & $3(6 \%)$ & $15(30 \%)$ & $18(12 \%)$ & \\
\hline \multicolumn{5}{|c|}{ Phase 4: 5 min after the completion of the instrumentation of root canal } & $0.035^{*}$ \\
\hline Rating 1 & $0(0 \%)$ & $0(0 \%)$ & $0(0 \%)$ & $0(0 \%)$ & \\
\hline Rating 2 & $5(10 \%)$ & $2(4 \%)$ & $0(0 \%)$ & $7(4.7 \%)$ & \\
\hline Rating 3 & $45(90 \%)$ & $48(96 \%)$ & $48(96 \%)$ & $141(94 \%)$ & \\
\hline Rating 4 & $0(0 \%)$ & $0(0 \%)$ & $2(4 \%)$ & $2(1.3 \%)$ & \\
\hline
\end{tabular}

Chi-Square test [+ Suggestive significance- $p$ value: $0.05<p<0.10,{ }^{*}$ Moderately significant- $p$ value: $0.01<p \leq 0.05,{ }^{* *}$ Strongly significant $-p$ value: $\leq 0.01$ ]

as a cooperation enhancing approach for child patients. ${ }^{19}$ Authors have defined the short treatment duration as less than 30 minutes and the long duration as more than 45 minutes. ${ }^{21,22}$ As the duration of the procedure increases, children become restless and show negative behavior. ${ }^{43}$ The approximate time required for a single visit pulpectomy is 45-60 minutes. Additionally, children will exhibit the maximum potential of cooperation in the initial 30 minutes. Hence, to keep the duration of treatment short and uniform, we completed 
Root Canal Instrumentation Time and Anxiety and Behavior

Table 5: Dental anxiety experienced according to gender and age during second visit of pulpectomy

\begin{tabular}{|c|c|c|c|c|c|c|c|c|}
\hline \multirow{2}{*}{$\begin{array}{l}\text { Scoring of } \\
\text { anxiety ex- } \\
\text { perienced }\end{array}$} & \multicolumn{2}{|l|}{ Gender } & \multirow{2}{*}{$\begin{array}{l}\text { Total } \\
(n=150)\end{array}$} & \multicolumn{4}{|l|}{ Age in years } & \multirow{2}{*}{$\begin{array}{l}\text { Total } \\
(n=150)\end{array}$} \\
\hline & $\begin{array}{l}\text { Female } \\
(n=68)\end{array}$ & $\begin{array}{l}\text { Male } \\
(n=82)\end{array}$ & & $\begin{array}{l}4 \\
(n=31)\end{array}$ & $\begin{array}{l}5 \\
(n=55)\end{array}$ & $\begin{array}{l}6 \\
(n=42)\end{array}$ & $\begin{array}{l}7 \\
(n=22)\end{array}$ & \\
\hline \multicolumn{9}{|c|}{ Phase 1: 5 min before the start of the instrumentation of root canal } \\
\hline Score 0 & $48(70.6 \%)$ & $58(70.7 \%)$ & 106 (70.7\%) & 19 (61.3\%) & $37(67.3 \%)$ & $28(66.7 \%)$ & $22(100 \%)$ & $106(70.7 \%)$ \\
\hline Score 1 & $20(29.4 \%)$ & $24(29.3 \%)$ & $44(29.3 \%)$ & $12(38.7 \%)$ & $18(32.7 \%)$ & $14(33.3 \%)$ & $0(0 \%)$ & $44(29.3 \%)$ \\
\hline Score 2 & $0(0 \%)$ & $0(0 \%)$ & $0(0 \%)$ & $0(0 \%)$ & $0(0 \%)$ & $0(0 \%)$ & $0(0 \%)$ & $0(0 \%)$ \\
\hline Score 3 & $0(0 \%)$ & $0(0 \%)$ & $0(0 \%)$ & $0(0 \%)$ & $0(0 \%)$ & $0(0 \%)$ & $0(0 \%)$ & $0(0 \%)$ \\
\hline$p$-value & 1.000 & & & $p$-value & $0.003^{* *}$ & & & \\
\hline \multicolumn{9}{|c|}{ Phase 2: During instrumentation of root canal } \\
\hline Score 0 & $31(45.6 \%)$ & $39(47.6 \%)$ & $70(46.7 \%)$ & $12(38.7 \%)$ & $21(38.2 \%)$ & $19(45.2 \%)$ & $18(81.8 \%)$ & $70(46.7 \%)$ \\
\hline Score 1 & $19(27.9 \%)$ & $26(31.7 \%)$ & $45(30 \%)$ & $12(38.7 \%)$ & $18(32.7 \%)$ & $15(35.7 \%)$ & $0(0 \%)$ & $45(30 \%)$ \\
\hline Score 2 & $14(20.6 \%)$ & $16(19.5 \%)$ & $30(20 \%)$ & $5(16.1 \%)$ & $14(25.5 \%)$ & $7(16.7 \%)$ & $4(18.2 \%)$ & $30(20 \%)$ \\
\hline Score 3 & $4(5.9 \%)$ & $1(1.2 \%)$ & $5(3.3 \%)$ & $2(6.5 \%)$ & $2(3.6 \%)$ & $1(2.4 \%)$ & $0(0 \%)$ & $5(3.3 \%)$ \\
\hline$p$-value & 0.497 & & & $p$-value & $0.008^{* *}$ & & & \\
\hline \multicolumn{9}{|c|}{ Phase 3: Immediately after instrumentation of root canal } \\
\hline Score 0 & $38(55.9 \%)$ & $46(56.1 \%)$ & $84(56 \%)$ & $15(48.4 \%)$ & $27(49.1 \%)$ & $22(52.4 \%)$ & $20(90.9 \%)$ & $84(56 \%)$ \\
\hline Score 1 & $17(25 \%)$ & $25(30.5 \%)$ & $42(28 \%)$ & $11(35.5 \%)$ & $18(32.7 \%)$ & $13(31 \%)$ & $0(0 \%)$ & $42(28 \%)$ \\
\hline Score 2 & $12(17.6 \%)$ & $10(12.2 \%)$ & $22(14.7 \%)$ & $5(16.1 \%)$ & $9(16.4 \%)$ & $6(14.3 \%)$ & $2(9.1 \%)$ & $22(14.7 \%)$ \\
\hline Score 3 & $1(1.5 \%)$ & $1(1.2 \%)$ & $2(1.3 \%)$ & $0(0 \%)$ & $1(1.8 \%)$ & $1(2.4 \%)$ & $0(0 \%)$ & $2(1.3 \%)$ \\
\hline$p$-value & 0.773 & & & $p$-value & $0.020^{*}$ & & & \\
\hline \multicolumn{9}{|c|}{ Phase 4: 5 min after the completion of the instrumentation of root canal } \\
\hline Score 0 & $68(100 \%)$ & $79(96.3 \%)$ & $147(98 \%)$ & $31(100 \%)$ & $54(98.2 \%)$ & $40(95.2 \%)$ & $22(100 \%)$ & $147(98 \%)$ \\
\hline Score 1 & $0(0 \%)$ & $3(3.7 \%)$ & $3(2 \%)$ & $0(0 \%)$ & $1(1.8 \%)$ & $2(4.8 \%)$ & $0(0 \%)$ & $3(2 \%)$ \\
\hline Score 2 & $0(0 \%)$ & $0(0 \%)$ & $0(0 \%)$ & $0(0 \%)$ & $0(0 \%)$ & $0(0 \%)$ & $0(0 \%)$ & $0(0 \%)$ \\
\hline Score 3 & $0(0 \%)$ & $0(0 \%)$ & $0(0 \%)$ & $0(0 \%)$ & $0(0 \%)$ & $0(0 \%)$ & $0(0 \%)$ & $0(0 \%)$ \\
\hline$p$-value & 0.252 & & & $p$-value & 0.665 & & & \\
\hline
\end{tabular}

Chi-square test [+ Suggestive significance- $p$ value: $0.05<p<0.10,{ }^{*}$ Moderately significant- $p$ value: $0.01<p \leq 0.05,{ }^{* *}$ Strongly significant- $p$ value: $\leq 0.01$ ]

the pulpectomy procedure in two appointments of not more than 30 minutes. Further, no difference in pain and success was observed in single or multiple visits pulpectomy. ${ }^{44-48}$ In addition, a shorter treatment duration gives the child a feeling of having co-operated well with the dental team. Further, it has been stated that the determination of behavior over a short period is more accurate than a long period. ${ }^{49}$ Furthermore, to reach a high correlation between ratings and behavior relatively short period (6-30 minutes) is recommended..$^{50}$ Researchers have advocated shorter appointment time until the child gains self-confidence and a good rapport is established with the pediatric dentist. ${ }^{51}$ Conversely, other authors concluded that longer appointments did not necessarily always associated with negative behavior in children. ${ }^{21,42}$ The difference in the study population, sample size, design, and categorizing the subjects based on age-groups rather than individual ages may partially reflect the observed disagreement.

In the first visit, as expected, greater anxiety was recorded during the administration of local anesthesia. Fear of the needle, the discomfort of the injection, and the lack of control of the situation cause high levels of anxiety. It may be due to the effective administration of local anesthesia, the children experienced lesser anxiety during other phases of the first visit. During the second visit, the children experienced lesser anxiety and exhibited positive behavior. The absence of administration of local anesthesia, limited use of Airotor, and reduced root canal instrumentation time would have contributed to positive behavior and lesser anxiety. Thus, it suggests that dividing the longer duration of single visit pulpectomy into two shorter appointments and the use of a rotary file system can elicit better cooperation from children with lesser anxiety. Furthermore, with additional endurance and time from parents and practitioners, the treatment procedure can be made apprehension-free and at the same time instill a positive attitude about pediatric dentistry.

The duration of treatment has an effect on children's behavior during dental treatment. ${ }^{41}$ In pediatric dentistry, a decrease in the root canal instrumentation time will also reduce the patient's and dentist's fatigue, thus providing a faster, safer, and quality treatment. ${ }^{25,52}$ We observed a significant reduction in root canal instrumentation time with both rotary file systems compared to the manual file system, which was consistent with other studies. ${ }^{52-56}$ In addition, increased anxiety and negative behavior was significantly associated with the use of a manual file system. The children experienced less anxiety and exhibited positive behavior with rotary file systems. This shows that children can handle their fears and anxiety more efficiently with the rotary files system and it was more so with the use of the Kedo-S file system compared to the HERO Shaper rotary file system. This may be due to the greater number of files in the HERO Shaper rotary file system that is needed for sequential enlargement of root canals. The availability of Kedo-S rotary files in a simple three file system helps the operator to carry out the procedure more efficiently and quickly thus reducing anxiety in children. All these findings suggest that the use of a rotary file system is very essential to reduce anxiety among children to obtain better cooperation for the clinical procedural steps.

The pediatric dentist may feel more secure while treating cooperative children than children with negative behavior 
Root Canal Instrumentation Time and Anxiety and Behavior

Table 6: Behavior exhibited according to gender and age during second visit of pulpectomy

\begin{tabular}{|c|c|c|c|c|c|c|c|c|}
\hline \multirow{2}{*}{$\begin{array}{l}\text { Behavior } \\
\text { exhibited }\end{array}$} & \multicolumn{2}{|l|}{ Gender } & \multirow[b]{2}{*}{$\begin{array}{l}\text { Total } \\
(n=150)\end{array}$} & \multicolumn{4}{|l|}{ Age in years } & \multirow[b]{2}{*}{$\begin{array}{l}\text { Total } \\
(n=150)\end{array}$} \\
\hline & $\begin{array}{l}\text { Female } \\
(n=68)\end{array}$ & $\begin{array}{l}\text { Male } \\
(n=82)\end{array}$ & & $\begin{array}{l}4 \\
(n=31)\end{array}$ & $\begin{array}{l}5 \\
(n=55)\end{array}$ & $\begin{array}{l}6 \\
(n=42)\end{array}$ & $\begin{array}{l}7 \\
(n=22)\end{array}$ & \\
\hline \multicolumn{9}{|c|}{ Phase 1: 5 min before the start of the instrumentation of root canal } \\
\hline Rating 1 & $0(0 \%)$ & $0(0 \%)$ & $0(0 \%)$ & $0(0 \%)$ & $0(0 \%)$ & $0(0 \%)$ & $0(0 \%)$ & $0(0 \%)$ \\
\hline Rating 2 & $0(0 \%)$ & $4(4.9 \%)$ & $4(2.7 \%)$ & $0(0 \%)$ & $2(3.6 \%)$ & $1(2.4 \%)$ & $1(4.5 \%)$ & $4(2.7 \%)$ \\
\hline Rating 3 & $66(97.1 \%)$ & $73(89 \%)$ & $139(92.7 \%)$ & $31(100 \%)$ & $51(92.7 \%)$ & $36(85.7 \%)$ & $21(95.5 \%)$ & $139(92.7 \%)$ \\
\hline Rating 4 & $2(2.9 \%)$ & $5(6.1 \%)$ & $7(4.7 \%)$ & $0(0 \%)$ & $2(3.6 \%)$ & $5(11.9 \%)$ & $0(0 \%)$ & $7(4.7 \%)$ \\
\hline$p$-value & 0.120 & & & $p$-value & 0.200 & & & \\
\hline \multicolumn{9}{|c|}{ Phase 2: During instrumentation of root canal } \\
\hline Rating 1 & $0(0 \%)$ & $0(0 \%)$ & $0(0 \%)$ & $0(0 \%)$ & $0(0 \%)$ & $0(0 \%)$ & $0(0 \%)$ & $0(0 \%)$ \\
\hline Rating 2 & $0(0 \%)$ & $1(1.2 \%)$ & $1(0.7 \%)$ & $0(0 \%)$ & $1(1.8 \%)$ & $0(0 \%)$ & $0(0 \%)$ & $1(0.7 \%)$ \\
\hline Rating 3 & $55(80.9 \%)$ & $68(82.9 \%)$ & $123(82 \%)$ & $25(80.6 \%)$ & $43(78.2 \%)$ & $33(78.6 \%)$ & $22(100 \%)$ & $123(82 \%)$ \\
\hline Rating 4 & $13(19.1 \%)$ & $13(15.9 \%)$ & $26(17.3 \%)$ & $6(19.4 \%)$ & $11(20 \%)$ & $9(21.4 \%)$ & $0(0 \%)$ & $26(17.3 \%)$ \\
\hline$p$-value & 0.819 & & & $p$-value & 0.109 & & & \\
\hline \multicolumn{9}{|c|}{ Phase 3: Immediately after instrumentation of root canal } \\
\hline Rating 1 & $0(0 \%)$ & $0(0 \%)$ & $0(0 \%)$ & $0(0 \%)$ & $0(0 \%)$ & $0(0 \%)$ & $0(0 \%)$ & $0(0 \%)$ \\
\hline Rating 2 & $0(0 \%)$ & $3(3.7 \%)$ & $3(2 \%)$ & $0(0 \%)$ & $2(3.6 \%)$ & $1(2.4 \%)$ & $0(0 \%)$ & $3(2 \%)$ \\
\hline Rating 3 & 60 (88.2\%) & 69 (84.1\%) & 129 (86\%) & 27 (87.1\%) & 45 (81.8\%) & 35 (83.3\%) & 22 (100\%) & 129 (86\%) \\
\hline Rating 4 & $8(11.8 \%)$ & $10(12.2 \%)$ & $18(12 \%)$ & $4(12.9 \%)$ & 8 (14.5\%) & $6(14.3 \%)$ & $0(0 \%)$ & $18(12 \%)$ \\
\hline$p$-value & 0.406 & & & $p$-value & 0.421 & & & \\
\hline \multicolumn{9}{|c|}{ Phase 4: 5 min after the completion of the instrumentation of root canal } \\
\hline Rating 1 & $0(0 \%)$ & $0(0 \%)$ & $0(0 \%)$ & $0(0 \%)$ & $0(0 \%)$ & $0(0 \%)$ & $0(0 \%)$ & $0(0 \%)$ \\
\hline Rating 2 & $5(7.4 \%)$ & $2(2.4 \%)$ & $7(4.7 \%)$ & $1(3.2 \%)$ & $4(7.3 \%)$ & $1(2.4 \%)$ & $1(4.5 \%)$ & $7(4.7 \%)$ \\
\hline Rating 3 & $63(92.6 \%)$ & $78(95.1 \%)$ & $141(94 \%)$ & $30(96.8 \%)$ & $50(90.9 \%)$ & $40(95.2 \%)$ & $21(95.5 \%)$ & $141(94 \%)$ \\
\hline Rating 4 & $0(0 \%)$ & $2(2.4 \%)$ & $2(1.3 \%)$ & $0(0 \%)$ & $1(1.8 \%)$ & $1(2.4 \%)$ & $0(0 \%)$ & $2(1.3 \%)$ \\
\hline$p$-value & 0.146 & & & $p$-value & 0.949 & & & \\
\hline
\end{tabular}

Chi-square test [+ Suggestive significance- $P$ value: $0.05<P<0.10,{ }^{*}$ Moderately significant $P$ value: $0.01<P \leq 0.05,{ }^{* *}$ Strongly significant $-P$ value: $\leq 0.01$ ]

Table 7: Correlation between mean instrumentation time with anxiety and behavior between of three groups

\begin{tabular}{ccccc}
\hline & \multicolumn{2}{c}{ Anxiety experienced } & \multicolumn{2}{c}{ Behavior exhibited } \\
\cline { 2 - 5 } Groups & rvalue & $p$-value & rvalue & $p$-value \\
\hline Group 1 & -0.017 & 0.904 & -0.094 & 0.516 \\
Group 2 & -0.143 & 0.322 & -0.298 & 0.036 \\
Group 3 & 0.113 & 0.929 & 0.106 & 0.466 \\
\hline
\end{tabular}

Spearman correlation

during endodontic treatment. ${ }^{23}$ An Indian study reported that extractions and pulpectomies were the procedures that brought out negative behavior in pediatric patients, especially during treatment. ${ }^{57}$ However, a study from Brazil reported that anxiety and negative behavior in children was not associated with endodontic or extraction procedure. ${ }^{23}$ These studies assessed the effect of the endodontic procedure on a child's anxiety and behavior but not the effect of root canal instrumentation time per se. Other studies have investigated the children's anxiety and behavior during invasive and non-invasive treatment. ${ }^{4,5,8,10,58}$ However, to the best of our knowledge none of the studies have assessed the effect of duration of root canal instrumentation on children's anxiety and behavior. Thus, it makes it difficult to compare the present results to previous findings.

The limitations of this study are the small sample size with homogenous, non-probabilistic children without a previous dental experience and the non-recording of physiological parameters of children during the clinical procedure. Further, all practitioners may not perceive behavior exhibited by children in the same manner and they tolerate children's behavior differently. ${ }^{59,60}$ Thus extrapolation of the results to different populations and cultural societies should be carefully weighed considering each clinical scenario. Future longitudinal studies are recommended focusing not only on single anxiety and behavior elements but also on the multi-dimensional assessment of children, which includes emotional, cognitive, behavioral, and physiological components and response systems.

The results of this study encourages the dentist to perform endodontic treatment of the primary dentition more efficiently, as the use of rotary instruments was not associated with greater dental anxiety or negative behavior. The clinician should emphasize the need of preserving the primary teeth by endodontic treatment to the parents/caregivers. Additionally, the use of a rotary file system increases the acceptance rate for endodontic treatment. Further, the results help to decrease the caregiver's apprehension about endodontic treatment, as they may have the perception of pain during their treatment of permanent teeth. ${ }^{23}$ 


\section{Conclusion}

The children treated with rotary file systems experienced less anxiety and exhibited positive behavior compared to children treated with the manual file system. Therefore, the pediatric dentist should consider conditioning and gradual exposure of children to dental operatory to obtain cooperation in young children, and to maintain their cooperation by making the duration of treatment as short as possible.

\section{References}

1. Cohen SM, Fiske J, Newton JT. The impact of dental anxiety on daily living. Br Dent J 2000;189:385-390. DOI: 10.1038/sj.bdj.4800777

2. Abanto J, Vidigal EA, Carvalho TS, et al. Factors for determining dental anxiety in preschool children with severe dental caries. Braz Oral Res 2017;31:1-7. DOI: 10.1590/1807-3107bor-2017.vol31.0013

3. Tickle M, Jones C, Buchannan K, et al. A prospective study of dental anxiety in a cohort of children followed from 5 to 9 years of age. Int J Paediatr Dent 2009;19:225-232. DOI: 10.1111/j.1365-263X.2009.00976.x

4. Santamaria RM, Innes NP, Machiulskiene V, et al. Acceptability of different caries management methods for primary molars in a RCT. Int J Paediatr Dent 2015;25:9-17. DOI: 10.1111/ipd.12097

5. Cademartori MG, Martins $P$, Romano AR, et al. Behavioral changes during dental appointments in children having tooth extractions. J Indian Soc Pedod Prev Dent 2017; 35:223-228. DOI: 10.4103/jisppd. jisppd_195_16

6. Mathur J, Diwanji A, Sarvaiya B, et al. Identifying dental anxiety in children's drawings and correlating it with Frankl's Behavior Rating Scale. Int J Clin Pediatr Dent 2017;10(1):24-28. DOI: 10.5005/jp-journals-10005-1401

7. Gustafsson A, Broberg A, Bodin L, et al. Dental behavior management problems: the role of child personal characteristics. Int J Paediatr Dent 2010;20:242-253. DOI: 10.1111/j.1365-263X.2010.01046.x

8. Morgan AG, Rodd HD, Porritt JM, et al. Children's experiences of dental anxiety. Int J Paediatr Dent 2017;27:87-97. DOI: 10.1111/ipd.12238

9. American Academy of Pediatric Dentistry (AAPD). Guideline on behavior guidance for the pediatric dental patient. Pediatr Dent 2016;38:185-198.

10. Cademartori MG, Rosa DP, Oliveira LJC, et al. Validity of the Brazilian version of the Venham's behavior rating scale. Int J Paediatr Dent 2017;27:120-127. DOI: 10.1111/ipd.12231

11. Ten Berge M, Veerkamp JS, Hoogstraten J, et al. Childhood dental fear in the Netherlands: Prevalence and normative data. Community Dent Oral Epidemiol 2002;30:101-107. DOI:10.1034/ j.1600-0528.2002.300203.x

12. Klingberg G. Dental anxiety and behavior management problems in paediatric dentistry - a review of background factors and diagnostics. Eur Arch Paediatr Dent 2008;9:11-15. DOI: 10.1007/BF03262650

13. Aminabadi NA, Sohrabi A, Erfanparast LK, et al. Can birth order affect temperament, anxiety and behavior in 5 to 7 -year-old children in the dental setting? J Contemp Dent Pract 2011;12(4):225-231. DOI: 10.5005/jp-journals-10024-1039

14. Barr ES, Kleier DJ, Barr NV. Use of nickel-titanium rotary files for root canal preparation in primary teeth. Pediatr Dent 1999;21:453-454.

15. Barr ES, Kleier DJ, Barr NV. Use of nickel-titanium rotary files for root canal preparation in primary teeth. Pediatr Dent 2000;22:77-78.

16. Subramaniam P, Girish Babu KL, Tabrez TA. Effectiveness of rotary endodontic instruments on Smear layer removal in root canals of primary teeth: a scanning electron microscopy study. J Clin Pediatr Dent 2016;40:141-146. DOI: 10.17796/1053-4628-40.2.141

17. Subramaniam P, Tabrez TA, Girish Babu KL. Microbiological assessment of root canals following use of rotary and manual instruments in primary molars. J Clin Pediatr Dent 2013;38:123-127. DOI: $10.17796 / j c p d .38 .2 . j 84265 t 82 u 60271 u$

18. Jeevanandan G, Govindaraju L. Clinical comparison of Kedo-S paediatric rotary files vs manual instrumentation for root canal preparation in primary molars: a double blinded randomised clinical trial. Eur Arch Paediatr Dent 2018;19:273-278. DOI: 10.1007/s40368-018-0356-6

19. Aminabadi NA, Oskouei SG, Farahani RM. Dental treatment duration as an indicator of the behavior of 3-to 9-year-old pediatric patients in clinical dental settings. J Contemp Dent Pract 2009;10(5):E025-32. DOI:10.5005/jcdp-10-5-23

20. GetzT, Weinstein P. The effect of structural variables on child behavior in the operatory. Pediatr Dent 1981;3(3):262-266.

21. Lenchner $\mathrm{V}$. The effect of appointment length on behavior of the pedodontic patient and his attitude toward dentistry. J Dent Child 1966;33(2):61-74.

22. Davidovich E, Wated A, Shapira J, et al. The influence of location of local anesthesia and complexity/duration of restorative treatment on children's behavior during dental treatment. Pediatr Dent 2013;35(4):333-336.

23. Soares JP, Cardoso M, Bolan M. Demystifying behavior and dental anxiety in schoolchildren during endodontic treatment for primary teeth-controll clinical trial. Int J Paediatr Dent 2019;29:249-256. DOI: 10.1111/ipd.12468

24. Bawazir OA, Salama FS. Clinical evaluation of root canal obturation methods in primary teeth. Pediatr Dent 2006;28:39-47.

25. Morankar R, Goyal A, Gauba K, et al. Manual versus rotary instrumentation for primary molar pulpectomies- A 24 months randomized clinical trial. Pedi Dent J 2020;28:96-102. DOI:10.1016/J.PDJ.2018.02.002

26. Venham LL, Gaulin-Kremer E, Munster E, et al. Interval rating scales for children' dental anxiety and uncooperative behavior. Pediatr Dent 1980;2:195-202.

27. FrankI SN, Shiere FR, Fogels HR. Should the parent remain with the child in the dental operatory? ASDC J Dent Child 1962;29:150-162.

28. Melamed BG. Methodological needs and behavioral research with child dental patients. Anesth Prog 1986;33:34-40.

29. Asl AN, Shokravi M, Jamali Z, et al. Barriers and drawbacks of the assessment of dental fear, dental anxiety and dental phobia in children: a critical literature review. J Clin Pediatr Dent 41(6):399-423. DOI: 10.17796/1053-4628-41.6.1

30. Chellappah NK, Vignehsa H, Milgrom P, et al. Prevalence of dental anxiety and fear in children in Singapore. Community Dent Oral Epidemiol 1990;18:269-271. DOI: 10.1111/j.1600-0528.1990.tb00075.x

31. Bankole OO, Aderinokun GA, et al. Maternal and child's anxiety Effect on child's behavior at dental appointments and treatments. Afr J Med MedSci 2002;31:349-352.

32. Ten Berge M, Veerkamp JS, Hoogstraten J. The etiology of childhood dental fear: the role of dental and conditioning experiences. J Anxiety Disord 16(3):321-329. DOI: 10.1016/s0887-6185(02)00103-2

33. Oliveira MM, Colares V. The relationship between dental anxiety and dental pain in children aged 18 to 59 months: a study in Recife, Pernambuco State, Brazil. Cad Saude Publica 2009;25(4):743-750. DOI: $10.1590 /$ s0102-311×2009000400005

34. Armfield JM, Heaton LJ. Management of fear and anxiety in the dental clinic: a review. Aust Dent J 2013;58(4):390-407. DOI: 10.1111/adj.12118

35. Shapiro DN. Reactions of children to oral surgery experience. J DentChild1967; 34:97-107.

36. Rud B, Kisling E. The influence of mental development on children's acceptance of dental treatment. Scand J Dent Res 1973;81:343-352. DOI: 10.1111/j.1600-0722.1973.tb00337.x

37. Ripa LW. Children's reaction to the dental experience. In Ripa LW, Barenie JT, (eds.) Management of dental behavior in children. Littleton, Mass: PSG Publishing Co; 1979:pp. 1-11.

38. Wilson SW. Non-pharmacologic issues in pain perception and control. In Pinkham JR, Casamassimo PS, Fields HW, Mc Tigue DJ, and Nowak A, (eds.) Pediatric dentistry: infancy through adolescence. 4th ed. Philadelphia, Pa: WB Saunders Co; 2005:pp. 96-107.

39. Suprabha BS, Rao A, Choudhary S, et al. Child dental fear and behavior: the role of environmental factors in a hospital cohort. J Indian Soc Pedod Prev Dent 2011;29:95-101. DOI: 10.4103/0970-4388.84679 
40. Kyritsi MA, Dimou G, Lygidakis NA. Parental attitudes and perceptions affecting children's dental behavior in Greek population. A clinical studyEur Arch Paediatr Dent 2009;10:29-32. DOI: 10.1007/BF03262664

41. Jamali Z, Najafpour $E$, Adhami ZA, et al. Does the length of dental procedure influence children's behavior during and after treatment? A systematic review and critical appraisal. J Dent Res Dent Clin Dent Prospects 2018;12(1):68-76. DOI: 10.15171/joddd.2018.011

42. Taylor MH, Moyer IN, Peterson DS. Effect of appointment time, age, and gender on children's behavior in a dental setting. ASDC J Dent Child 1983;50:106-110.

43. Wright GZ, Alpern GD. Variable's influencing children's cooperative behavior at the first dental visit. ASDC J DentChild 1971;38(2):124-128.

44. Roane JB, Dryden JA, Grimes EW. Incidence of postoperative pain after single - and multiple - visit endodontic procedures. Oral Surg 1983;55:68-72. DOI: 10.1016/0030-4220(83)90308-0

45. Fava LR. A comparison of one versus two appoints endodontic therapy in teeth with non-vital pulps. Int Endod J 1989;22:179-183. DOI: 10.1111/j.1365-2591.1989.tb00921.x

46. Eleazer PD, Eleazer KR. Flare-up rate in pulpally necrotic molars in one- visit versus two-visit endodontic treatment. J Endod 1998;24:614-616. DOI: 10.1016/S0099-2399(98)80122-2

47. Ince $B$, Ercan $E$, Dali $M$, et al. Incidence of postoperative pain after single- and multi-visit endodontic treatment in teeth with vital and non-vital pulp. Eur J Dent 2009;3:273-279.

48. Singla R, Marwah N, Dutta S. Single versus multiple visit root canal therapy. Int J Clin Peadiatr Dent 2008;1:17-24. DOI: 10.5005/jp-journals-10005-1004

49. Allen KD, Stanley RT, McPherson K. Evaluation of behavior management technology dissemination in pediatric dentistry. Pediatr Dent 1990;12(2):79-82.

50. Allen KD, Hutfless S, Larzelere R. Evaluation of two predictors of child disruptive behavior during restorative dental treatment. J Dent Child (Chic) 2003; 70(3):221-225.

51. Richardson RW, Richardson LA. Birth order and you: Discover how your sex and position in the family affects your personality, career, relationships, and parenting (Self-Counsel Personal Self-help) (2nd ed). North Vancouver, British Columbia: Self Counsel Press 2000.

52. Ochoa-Romero T, Mendez-Gonzalez V, Flores-Reyes $\mathrm{H}$, et al. Comparison between rotary and manual techniques on duration of instrumentation and obturation times in primary teeth. J Clin Pediatr Dent 2011;35(4):359-363. DOI: 10.17796/jcpd.35.4.8k013k21t39245n8

53. Musale PK, Mujawar Evaluation of the efficacy of rotary vs. hand files in root canal preparation of primary teeth in vitro using CBCTSAV. Eur Arch Paediatr Dent 2014;15:113-120. DOI: 10.1007/s40368-013-0072-1

54. Makarem A, Ravandeh N, Masoumeh E. Radiographic assessment and chair time of rotary instruments in the pulpectomy of primary second molar teeth: a randomized controll clinical trial. J Dent Res Dent Clin Dent Prospects 2014; 8:84-89. DOI: 10.5681/joddd.2014.015

55. Silva LA, Leonardo MR, Nelson-Filho $P$, et al. Comparison of rotary and manual instrumentation techniques on cleaning capacity and instrumentation time in deciduous molars J Dent Child (Chic) 2004;71:45-47.

56. Crespo S, Cortes O, Garcia C, et al. Comparison between rotary and manual instrumentation in primary teeth. J Clin Pediatr Dent 2008;32:295-298. DOI: 10.17796/jcpd.32.4.157136355u606576

57. Sivakumar $P$, Gurunathan D. Behavior of children toward various dental procedures. Int J Clin Pediatr Dent 2019;12(5):379-384. DOI: 10.5005/jp-journals-10005-1670

58. Pai R, Mandroli P, Benni D, et al. Prospective analysis of factors associated with dental behavior management problems, in children aged 7-11 years. J Indian Soc Pedod Prev Dent 2015;33:312-318. DOI: 10.4103/0970-4388.165684

59. Veerkamp JSJ, Wright GZ. Children's behavior in the dental office. In: Wright GZ, Kupietzky A. Behavior management in dentistry for children (2nd ed.). Lowa: Wiley Blackwell, John Wiley \& Sons, Inc. 2014. pp. 23-33.

60. Subramaniam P, Haqh M, Gupta M. Assessment of trait and state anxiety in 3-6-year-old children during sequential phases of dental treatment. Contemp Pediatr Dent 2020;1(1):22-32. 